\title{
Ensuring the Validity of Technical Skill Assessment Outcomes in Technology Education in Nigeria
}

\author{
Nkechi Patricia-Mary Esomonu \\ Nnamdi Azikiwe University, Awka, Nigeria \\ Martins Ndibem Esomonu \\ Federal College of Education (Technical), Umunze, Nigeria \\ Gbenga Kayode Oluwatoyo \\ Nnamdi Azikiwe University, Awka, Nigeria
}

\begin{abstract}
A prominent drawback to the economic advancement of Nigeria is the lack of right and adequate technical manpower to drive the technological institutions in the country. One factor of such challenge is the outcomes of classroom assessment. Assessment at the classroom level places great tasks at the shoulders of teachers and evaluators. The tasks increasingly manifest in technology education, where scores awarded should of necessity translate to technical skills acquired. Though a recent study has shown that the products of technology education of Nigerian Certificate in Education (NCE) programmes posses knowledge and skills that enable them perform creditably at their workplaces, but there still seem to be some gap between the grades they earn at graduation and the skills they possess. The need to make the technology education graduates in Nigeria internationally acceptable in terms of skill acquisition still remains a problem. Hence, the study sets out to ascertain activities that will ensure the validity of skill assessment scores in technology education. Six research questions and two null hypotheses guided the study. The population of the study consists of 104 technology education teachers in tertiary institutions in South East, Nigeria. There was no sampling, because the entire population was not very large, and therefore, were all used for the study. The instrument for data collection was questionnaire. The results showed that some teacher development activities, teachers' application of item construction procedure, content delivery issues, and facilities for teaching and conducting examinations will ensure valid interpretation of skill assessment outcomes. The ratings of the activities by male and female, and less or more experienced teachers did not differ. It was recommended among others that government and implementers of technology education should be encouraged to allow the identified conditions to operate in technology education in Nigeria.
\end{abstract}

Keywords: assessment outcomes, validity, technical skill, technology education, evaluation

\section{Introduction}

Technological, industrial and economic fortune of any nation is directly related to the quality and quantity of the technical workforce. Hence, Jibrin and Nuhu (2010) emphasized that rapid technological and industrial

\footnotetext{
Nkechi Patricia-Mary Esomonu, Professor, Department of Educational Foundations, Nnamdi Azikiwe University. Martins Ndibem Esomonu, Engineer, School of Industrial Technical Education, Federal College of Education (Technical). Gbenga Kayode Oluwatoyo, Lecturer II, Department of Educational Foundations, Nnamdi Azikiwe University.
} 
development are anchored on technical skill acquisition and industrial experience among others.

According to Idris (2004), technical education leads to the acquisition of practical experience to enable the individual acquire knowledge and skill for direct solution of problems of the society. Idris (2004) further noted that sometimes technical education and technological education are used interchangeably which he said agrees with the United Nations Educational, Scientific, and Cultural Organization (UNESCO) definition of technology education as educational process which involve the study of technological and related sciences and the acquisition of practical skills and knowledge relating to occupation in various sectors of economic and local life.

\section{Literature Review}

Technical skill as captioned in this study is predominantly acquired through technology education programmes run in Nigeria in some Faculties of Education of Universities, Colleges of Education (Technical) and some Polytechnics. Technology education deals with training of technical personnel for the purpose of initiating, facilitating, and implementing the technological development of a nation and also to create the basic awareness of technological literacy in the youths (Uwaifo, 2010). Technology education programme is designed to develop in individuals technical and applied skills and basic scientific knowledge. It helps to develop abilities, understanding, attitudes, and work habits that enable individual to have gainful employment and progress in it. It involves specific knowledge and abilities required for success in a job (Investopedio, 2014). Technical skills are skills required for accomplishment of a specific task. They are those abilities acquired through learning and practice which are often job or task specific.

Technical skills are also referred to as "hard skill." They are specific teachable abilities that can be defined and measured. The questions now are how are these technical skills defined, taught, and measured? Are the outcomes of these technical skills assessment valid? Validity is the extent to which scores on a test enable one to make meaningful and appropriate interpretations. If tests scores or assessment data are not obtained with instruments that allow valid and reliable interpretation, one can have little faith in the results attained or the conclusions drawn from the results.

Validity as defined by American Educational Research Association, the National Council on Measurement in Education, and the American Psychological Association (1999) is "the degree to which evidence and theory support the interpretation of test scores entailed by proposed use of tests" (p. 9).

Validity of technical skill assessment outcomes entails credibility of the assessment outcomes. Consequently, the scores and the certificates awarded thereafter are true indices of the skills acquired by the students. It does appear that there are some deviation between the certificates and the technical skills acquired by graduates of technology education in Nigeria. For instance, Galadima as cited in Esomonu (2006) observed that a gap exists between theory and practice in vocational and technical programmes. Fasina and Ugonabo in Esomonu (2006) reported cases of inadequate supply of technical teachers that are the facilitators of the technical skills in schools of vocational and technical education. Evaluation of the products of the Nigerian vocational and technical education programme published in 2006 showed that the knowledge and skills of Nigerian Certificate in Education (NCE) graduates were adequate to enable them perform creditably at job (Esomonu, 2006). The questions are to what extent the system can sustain this finding and to what extent can the graduates compete in the global best practices. In the National Policy on Education, it is stated that 
technology education in Nigeria is facing some challenges. Some of which include, low enrolment, infrastructural delay, inadequate equipment, and poor learning outcomes (Federal Republic of Nigerian, 2013).

Skills acquisition requires well developed and resourceful technical teachers. These teachers should of necessity operate within appropriate environment. The teachers and students should have appropriate facilities and consumables for students to acquire technical skills. Teacher development is a very important factor in continuous good performance of teachers. Through the retaining, teachers learn the current practices in their area. Technical teachers particularly need retraining in industries to be able to prepare the students to comfortably take up jobs in industries.

In terms of constructing instruments that will collect valid and reliable data, Nwankwo (2011) found that teachers are not fully aware and do not use most of the skills for item generation. There is need therefore to identify issues and practices that will improve the validity of assessment outcomes in technology education. Consequently, the study ascertained the activities that will ensure the validity of technical skill assessment scores in technology education.

\section{Research Questions}

The research was guided by the research questions stated below.

1. What are the teacher development activities that ensure the validity of technical skill assessment outcomes?

2. What are the item generation procedure applied by teachers that ensures the validity of technical skill assessment outcomes.

3. What are the content delivery issues that ensure the validity of technical skill assessment outcomes?

4. What are the facilities for teaching and examination that ensure the validity of technical skill assessment outcomes?

5. What are the mean ratings of male and female teachers on activities that ensure the validity of technical skill assessment outcomes?

6. What are the mean ratings of less and more experienced teachers on items that ensure the validity of technical skill assessment outcomes?

\section{Null hypotheses}

\section{Hypothesis 1}

At 0.05 alpha level, there is no significant difference between the mean of ratings of male and female teachers on the activities that ensure validity of technical skill assessment outcomes.

\section{Hypothesis 2}

At $5 \%$ significant level, the mean of ratings of less and more experienced teachers on the activities that ensure validity of technical skill assessment outcomes will not differ.

\section{Method}

The study is a survey research carried out in tertiary institutions in South East of Nigeria. The population of the study consisted of 104 technology education teachers. There was no sampling, because the population size was not large, therefore, the entire population was used for the study. The instrument of data collection was 30 item questionnaire which has five sections. 
Section A contains teacher variables. Section B was on teacher development activities. Section C, item generation procedure; Section D, content delivery issues; and Section E was on facilities for teaching and examination. Sections B to E, therefore, were on activities that ensure validity of outcomes of technical skill assessment. After administration of instrument, only 102 returned their questionnaire.

Mean and standard deviation were used to answer the research questions and $t$-test of independent sample was used to test the null hypothesis. Any item that has a mean of 3.50 and above was accepted as an item that ensures validity of technical skill assessment outcomes.

\section{Results}

All the seven items are accepted as teacher development activities that ensure the validity of technical skill assessment outcome (see Table 1).

Table 1

Means and Standard Deviations of Teacher Development Activities

\begin{tabular}{lllll}
\hline$S / N$ & Item & Mean & $S D$ & Decision \\
\hline & Teachers attending: & & & \\
1 & Retraining courses in industries in the use of modern equipment. & 4.65 & 0.48 & Accepted \\
2 & Workshop in item construction skill. & 4.29 & 0.60 & Accepted \\
3 & Seminar on lesson preparation. & 4.02 & 0.83 & Accepted \\
4 & Workshop on knowledge on new development in course content. & 4.45 & 0.54 & Accepted \\
5 & Seminar on lesson delivery. & 4.11 & 0.88 & Accepted \\
6 & Workshop on practical skill on new development in course content. & 4.45 & 0.698 & Accepted \\
7 & Clinical supervision of teachers by experts and professionals. & 3.94 & 1.00 & Accepted \\
Total & & 4.27 & 0.44 & \\
\hline
\end{tabular}

All the items are accepted as item generation procedure, teachers should apply to ensure validity of technical skill assessment outcomes (see Table 2).

Table 2

Means and Standard Deviations of Teachers' Application of item Generation Procedure

\begin{tabular}{lllll}
\hline$S / N$ & Item & Mean & $S D$ & Remark \\
\hline 1 & Determination of course content covered before setting questions. & 4.96 & 1.17 & Accepted \\
2 & Determination of educational objective before setting question. & 4.45 & 0.63 & Accepted \\
3 & Use of table of specification. & 4.94 & 0.44 & Accepted \\
4 & Assessment should cover cognitive, psychometric and affective domains. & 4.49 & 0.57 & Accepted \\
5 & Preparing marking guide while setting questions. & 4.06 & 0.75 & Accepted \\
6 & Generation of more questions than needed. & 3.41 & 1.09 & Accepted \\
Total & & 4.38 & 1.16 & \\
\hline
\end{tabular}

The seven items on content delivery issues are accepted as activities that ensure the validity of technical skill assessment outcomes (see Table 3).

All the items except Item 4 which stated that students take alternative to practical during examination, are accepted as facilities for teaching and examination that ensure validity of technical skill assessment outcomes (see Table 4). 
Table 3

Means and Standard Deviation of Content Delivery Issues

\begin{tabular}{lllll}
\hline$S / N$ & Item & Mean & $S D$ & Remark \\
\hline & Use of: & & & \\
1 & Field trips & 4.47 & 0.67 & Accepted \\
2 & Supervised industrial training & 5.00 & 0.00 & Accepted \\
3 & Problem based learning & 4.92 & 0.60 & Accepted \\
4 & Peer group teaching/discussion & 4.33 & 0.73 & Accepted \\
5 & Workshop practical & 4.47 & 0.64 & Accepted \\
6 & Lecture & 4.37 & 0.63 & Accepted \\
7 & Project & 4.45 & 0.57 & Accepted \\
Total & & 4.59 & 1.13 & \\
\hline
\end{tabular}

Table 4

Means and Standard Deviation of Facilities for Teaching and Examination

\begin{tabular}{lllll}
\hline$S / N$ & Item & Mean & $S D$ & Remark \\
\hline 1 & Each student has access to the needed tools during practical. & 4.37 & 0.89 & Accepted \\
2 & Each student has access to the required equipment during practical. & 4.23 & 0.98 & Accepted \\
3 & Each student has required consumable to work with. & 3.80 & 1.14 & Accepted \\
4 & Student takes alternative to practical during examination. & 3.42 & 1.28 & Not accepted \\
5 & Adequate sitting arrangement for lecture. & 4.00 & 1.09 & Accepted \\
6 & Adequate sitting arrangement for examination. & 4.07 & 0.81 & Accepted \\
7 & Firefighting equipment in the workshop are available. & 4.00 & 0.86 & Accepted \\
8 & First aid box is available. & 3.90 & 1.01 & Accepted \\
9 & Workshop safety guide charts are available. & 3.76 & 1.10 & Accepted \\
10 & Standard lecture and examination halls are available. & 3.82 & 1.13 & Accepted \\
Total & & 3.96 & 0.62 & \\
\hline
\end{tabular}

According to Table 5, the males have a slightly higher mean than females.

Table 5

Means and Standard Deviations of Ratings of Male and Female Teachers on Activities That Ensure Validity of Technical Skill Assessment Outcomes

\begin{tabular}{lllll}
\hline Gender & $N$ & Mean & $S D$ & Std. error mean \\
\hline Male & 52 & 4.3141 & 0.43141 & 0.06789 \\
Female & 50 & 4.2200 & 0.44904 & 0.06380 \\
\hline
\end{tabular}

As shown in Table 6, the less experienced teachers have slightly higher mean with more veried scores.

Table 6

Means and Standard Deviations of Ratings of Less and More Experienced Teachers on Activities That Ensure Validity of Technical Skill Assessment Outcomes

\begin{tabular}{lllll}
\hline Years of experience & $N$ & Mean & $S D$ & Std. error mean \\
\hline $1-10$ & 43 & 4.2829 & 0.52303 & 0.79760 \\
11 and above & 59 & 4.2571 & 0.43196 & 0.05624 \\
\hline
\end{tabular}

According to the results in Table 7, the null hypothesis of no significant difference between the means is accepted. 
Table 7

Summary of t-Test on the Significant Difference of the Mean Ratings of Male and Female Teachers on Activities That Ensure Validity of Technical Skill Assessment Outcomes

$t$-test for equality of means

$95 \%$ confidence interval of the difference

Sig. mean Std. error $t \mathrm{df}$ ( $s$-tailed) difference difference lower upper

\begin{tabular}{lrrrrrrr}
\hline Equal variance assumed & 1.011 & 100.000 & 0.315 & 0.09410 & 0.09312 & 0.09064 & 0.27885 \\
Equal variance not assumed & 1.012 & 99.782 & 0.314 & 0.09410 & 0.09296 & 0.09033 & 0.27854 \\
\hline
\end{tabular}

Note. $p$-value $=0.315>$ alpha level $=0.05$.

According to the results in Table 8, the null hypothesis of no significant difference between the means is accepted.

Table 8

Summary of t-Test on the Significant Difference of the Mean Ratings of Less and More Experience Teachers as Activities That Ensure Validity of Technical Skill Assessment Outcome

$t$-test for equality of means

$95 \%$ confidence interval of the difference

Sig. mean Std. error $t \mathrm{df}$ ( $s$-tailed) difference difference lower upper

\begin{tabular}{lrrrrrrr}
\hline Equal Variance assumed & 0.273 & 100.000 & 0.785 & 0.02588 & 0.9471 & -0.16202 & 0.27885 \\
Equal Variance not assumed & 0.265 & 79.847 & 0.792 & 0.02588 & 0.9759 & -0.16834 & 0.27850 \\
\hline
\end{tabular}

Note. $p$-value, $0.785>$ alpha level 0.05 .

\section{Discussion}

All the items in teacher development activities are accepted as activities that ensure the validity of technical skill assessment of outcomes. Onyia and Esomonu (2012; 2013) noted that adequately supervised industrial training of students by both school- and industry- based supervisors will better the prospect of practical skills acquisition by trainees in technical institutions. Embarking on the guided field trips in well equipped industries and institution, organizing seminars, conference, workshops, allocation of adequate period for practical skills, and awards of practical excellence to students between technical institution and industries would improve the quality of skills acquired by trainees.

The six activities in item generation procedure were also accepted as activities the teacher will apply to ensure validity of the outcomes of technical skill assessment. Skill needs to be elicited and assessed for its proper development. More importantly competency needs to be ascertained before certification so that the certificates issued will be an indication of level attained and not attended (Esomonu, 2005).

The results of the study show the importance of the content delivery in ensuring that outcomes of the assessment are valid. Classroom interaction is so important that when it is not properly implemented the assessment will be baseless.

The results of the study have shown that facilities for teaching and examination are very important to achieve valid outcome of technical skill assessment. Hence, Okeowo and Adewuyi (2000) stated that optimum performance learning task in vocational and technical education would occur when appropriate instructional materials are used in teaching and examination. Nwankwo as cited in Esomonu (2014) emphasized that 
adequate workshop practice provides opportunity for direct perception and formation of concrete ideas as it will help the students to gain practical skills and work habit required to establish self on graduation. In the instrument, the use of alternative to practical during examination was rejected as an item that will ensure validity of outcomes of technical skill assessment. This reinforces, the importance of well equipped workshops and laboratories in technology education.

In all the activities that ensure validity of technical skill assessment outcomes, the mean differences of male and female teachers and less and more experienced teachers do not differ. This means that the issues of technical skill assessment outcomes were perceived in the same way by different groups of teachers. By implication, the findings of the study will achieve the desired objectives if implemented.

\section{Conclusion and Recommendations}

Based on the findings of the study, it was concluded that to ensure the validity of technical skill assessment outcomes in technology education, the understated activities should be done.

1. Teacher development activities which ranged from retraining in industries to clinical supervision of teachers by experts and professionals;

2. Teachers' application of item generation procedure which hanged from determination of course content covered before setting question to generation of more questions than needed;

3. Content delivery issues which ranged from use of field trips to use of project;

4. Facilities for teaching and examination which ranged from each student having access to the needed tools during practical to the use of standard laboratories, classrooms and halls.

It is therefore recommended that the government should make funds available for provision of equipped and functional laboratories, classrooms, halls, and retraining of teachers. The operators of technology education should implement the identified activities in their institutions. Teachers should upgrade themselves in new skills and knowledge and follow the procedure for item generation to ensure the validity of the technical skill assessment outcomes.

\section{References}

American Educational Research Association, American Psychological Association and National Council on Measurement in Education (1999). The standards for educational and psychological testing. Washington, D.C.: American Educational Research Association.

Esomonu, N. P. M. (2005). Reflecting an educational evaluation: The charm of the psychometricians (Inaugural Lecture Series No. 1 Federal College of Education [Technical] Umunze, Anambra State, Nigeria).

Esomonu, N. P. M. (2006). The evaluation of the products of the Nigeria vocational and technical education programma. Journal of Education Research and Polices. International Institutes for Educational Research, 1(1), 11-16.

Esomonu, M. N. (2014). Strategies for improving acquisition of practical skills in technical colleges in Anambra State (Thesis present to Enugu State University of Science and Technology, Enugu, Nigeria).

Federal Republic of Nigeria. (2013). National policy on education. Lagos: Nigeria Educational Research and Development Council.

Idris, O. M. (2004). Enhancing technology development in Nigeria through functional technological education. International Journal of Research in Education, 1(1\&2), 17-24.

Investopedia. (2014). Retrieved from http://www.investopedio.com/terms/technical-job-skill.asp

Jibrin, B. A., \& Nuhu, N. I. (2010). Parents' and teachers' perception of effectiveness of technical vocational education and training in Nigeria. Journal of Nigerian Association of Teachers of Technology, 7(1), 115-122.

Nwangwu, F. O. (2011). Awareness and use of item generation skills in test construction among secondary school teachers in Onitsha Educational Zones of Anambra States (Thesis submitted to Nnamdi Azikiwe University, Awka, Anambra State, Nigeria). 
Okeowo, S. O., \& Adewuyi, E. O. (2000). Importance of industrial materials in the teaching of vocational and technical education. In G. N. Nneji (Ed.), Technology education and the universal basic education in Nigeria (pp. 118-125). Lagos: Nigerian Association of Teachers of Technology.

Onyia, A. U., \& Esomonu, M. N. (2012). Industrial linkage activities for effective practical skills development of students in technical colleges in Anambra State, Nigeria. Journal of Science and Computer Education (JOSCED), 2(1), 25-36.

Onyia, A. U., \& Esomonu, M. N. (2013). Technical colleges management initiatives in practical skills acquisition of students. Journal of Technical Technology and Vocational Educators (JOTTAVE), 3(1), 128-134.

Uwaifo, V. O. (2010). Technical education and its challenges in Nigeria in the 21st century. International NGO Journal, 5(2), 40-44. Retrieved from http://www./academicjournals 